\title{
Mia Couto: representação e subalternidade em Mulheres de Cinza
}

\author{
Mia Couto: Representation and Subalternity \\ in Women of Ashes
}

José Paulo Cruz Pereira

Universidade do Algarve

\section{DoI}

https://doi.org/10.37508/rcl.2021.n45a426

\section{RESUMO}

A nossa leitura incide sobre: a) a representação da subalternidade em Mulheres de Cinza; $b$ ) as implicações de sentido do complexo processo de nomeação da voz narradora de Imani, transversal à trama ficcional dos três romances de As Areias do Imperador. Parte, com esse propósito, da ponderação do duplo sentido de "representação" em Can the Subaltern Speak?, de Gayatri Spivak, analisando: a) a forma como aí se alinham os pressupostos de $\mathrm{O} 18$ do Brumário de Louis Bonaparte, de Karl Marx, e de A Questão Meridional, de Antonio Gramsci, na descrição do seu conceito de subalterno; b) a forma como, em Mulheres de Cinza, se projeta a sua configuração do subalterno como excluído. Fá-lo pondo a descoberto quer a instância do neutro, de que nos fala Maurice Blanchot - em L'entretien infinit... -, quer a da singularidade, tal como Spivak a desdobra em An Aesthetic Education in the Era of Globalization - lidos como investidos numa das fábulas com as quais Mia Couto os alegoriza.

Palavras-Chave: representação; subalternidade; heterogeneidade; suspensão; neutro; testemunhar. 


\section{Abstract}

My reading focus on: a) the representation of subalternity in Women of Ashes; b) the semantic, as well as political and ethical implications of the complex process of the narrator's voice and name - the narrative voice that crosses the entire plot that intersects all the three different novels of The Sands of the Emperor. It starts, for that purpose, by pondering the twofold meaning of 'representation', in Can the Subaltern Speak?, by Gayatri C. Spivak, examining: a) the intersection of both Karl Marx's $18^{\text {th }}$ of Brumair of Louis Bonaparte and Antonio Gramsci's The Southern Question, in her description of the concept of the subaltern; b) the way it is possible to project the characteristic features of the subaltern as an excluded subject in Women of Ashes. It performs this by uncovering both the instance of the neuter as Blanchot defines it - in L'entretien infinit - and the instance of singularity, as Spivak also unfolds it, in An Aesthetic Eductation in the Era of Globalization - reading them in one of the fables with which Mia Couto allegorizes them.

KEYWORDS: representation; subalternity; heterogeneity; suspension; neuter; to bear witness.

\section{Introdução: subalternidade e heterogeneidade}

Abordar, hoje, a questão do sujeito subalterno é um gesto que é preciso situar, do ponto de vista das suas implicações teóricas. Nesse sentido, é Can the Subaltern Speak? - da autoria da crítica indiana pós-colonial Gayatri C. Spivak - o texto de que se torna necessário partir. No centro da sua argumentação estará, como o seu título sugere, a questão da representação. Em que termos? Naqueles determinados pela natureza do espaço sociocultural e ideológico em que a sua necessidade se impõe:

Simply by being postcolonial or member of an ethnic minority, we are not 'subaltern'. That word is reserved for the sheer heterogeneity of the decolonized space. When a line of communication is established between a member of subaltern groups and the circuits of citizenship or institutionality, the 
subaltern has been inserted into the long road to hegemony (SPIVAK, 2010, p. 65, grifo nosso).

A consideração da questão da heterogeneidade - mesmo num espaço aqui dito, stricto sensu, «descolonizado» - é crucial. Por um lado, porque é justamente a respeito do desfasamento entre formas distintas de codificação do valor, bem como do sentido da experiência e da existência, que a representação como questão se coloca. Como representar, aqui, o heterogéneo? Como fazê-lo sem, ao mesmo tempo, reinscrever as condições de reprodução da subalternidade? Com efeito, tal sociedade "descolonizada" é ainda herdeira de algumas das suas anteriores condições coloniais, quer de sujeição e, consequentemente, de exposição à violência epistémica imperialista, quer de disjunção hierárquica tradicional, inscrita na estrutura da sua estratificação social - por exemplo, de cariz patriarcal. Só por dentro e para lá dessa sujeição e dessa disjunção hierárquica tradicional se vão reconstruindo, politicamente, com a independência, os seus (re) posicio-namentos. Como nos diz Spivak em «Quem reivindica a alteridade?»:

Todos sabemos que (...) durante o período imediatamente anterior à conquista e consolidação territorial do monopólio capitalista, uma classe de funcionários / intelligentsia foi frequentemente produzida e funcionou como pára-choques entre os administradores e o território administrado. Estes eram 'sujeitos coloniais' formados, com diferentes graus de sucesso, geralmente, embora não invariavelmente, a partir da elite nativa (SPIVAK, 1994, p. 192).

A necessidade de formação desta «classe de funcionários» - que, com a sua mediação, pudesse amortecer o choque entre os interesses da administração colonial e as disposições próprias da sociedade e da cultura dos administrados - põe já em relevo, a contrario sensu, a importância da representação em política. Ao mesmo tempo, ela indica, de facto, a existência de outras classes, quer alienadas das 
formas hegemónicas da cultura dominante, quer por elas sujeitadas. Em Can the Subaltern Speak?, Spivak repro-duz, a este respeito, um passo dos Speeches by Lord Macauley em que se recortam, com bastante nitidez, os desígnios culturais e ideológicos, jurídico-políticos e administrativos da gestão do poder colonial britânico na Índia. A agenda colonial consagrava, aí, a figura daqueles a que, no caso das colónias portuguesas, se chamaria de assimilados:

We must at present do our best to form a class who may be interpreters between us and the millions whom we govern; a class of persons, Indian in blood and colour, but English in taste, in opinions, in morals, and intellect. To that class we may leave it to refine the vernacular dialects with terms of science borrowed from the Western nomenclature, and to render them by degrees fit vehicles for conveying knowledge to the great mass of the population (SPIVAK, 2010, p. 36).

Embora aqui se não designem, ainda, aqueles para cuja massa se orientariam, afinal, tais esforços de condicionamento e de produção ideológica - por via da educação e da lei, mas também da economia -, eles são claramente identificados: as classes subalternas são as dos «tribais» com os quais, no caso da Índia, se pretende estabelecer essa ponte de persuasão docilizadora, capaz de assegurar a efetividade do poder colonial britânico. Na história que Spivak analisa, em «Quem reivindica a alteridade?» - respeitante à sua leitura de The Hunt, de Mahasweta Devi -, é a personagem principal que se define em relação à figura do subalterno:

Mary Oraon. Oraon é o nome de uma das maiores das cerca de trezentas tribos da Índia. Em hindi, a linguagem nacional, os tribais são chamados de adivasis (habitantes originais). (...) Junto com as 'castas reguladas', - as castas hindus mais baixas (os sem-castas, os párias) - estes habitantes originais são os subalternos oficiais da República da Índia. Eles estão fora das sete re- 
ligiões listadas no hino nacional indiano: hinduísmo, budismo, sikhismo, jainismo, zoroastrismo, o islão e a cristandade. (...) (SPIVAK, 1994, p. 199, grifo nosso).

A figura do subalterno é pois, aqui, a do excluído. O que Mary Oraon é, por um lado, quer pelo facto de a sua ascendência materna determinar, nela, esse vínculo com os «habitantes originais» - «Esta é então Mary, simplesmente Oraon, simplesmente identifi-cada com a sua tribo" (SPIVAK, 1994, p. 199) -, quer ainda por ter nascido de uma relação impura e ilegítima, de estupro cometido por seu pai, que «foi um fazendeiro branco que violou sua mãe antes de deixar a Índia e ir para a Austrália» (SPIVAK, 1994, pp. 199-200). Tratar-se-ia, então, de uma dupla exclusão. Porque, por outro lado, esse duplo estatuto da sua ascendência (simultaneamente legítimo e ilegítimo; nacional e estrangeiro) configura, nela, uma espécie de quiasmo que a suspende de qualquer relação de simples-pertença: sendo ela «fruto de um estupro (...) ela não é uma tribal de verdade» (SPIVAK, 1994, p. 200). A questão da representação coloca-se, assim, no horizonte de um mundo pós-(/neo-)colonial capitalista que, marcado pela experiência do heterogéneo, é também o de uma certa ambivalência: Mary é e não é uma tribal. Essa ambivalência é já, ela mesma, indiciadora do exercício de uma certa violência: aqui não apenas literal (o estupro), mas também epistémica, isentando-a - no seu duplo estatuto de pária - de qual-quer atribuição originária. Embora enquanto «Oraon» Mary fosse «simplesmente identi-ficada com a sua tribo»:

(...) ela foi batizada como Maria; é descendente de tribais convertidos ao cristianismo por missionários. (...) Mary, empregada numa casa hindu, é e não é cristã. Todas as categorias apropriadas estão misturadas na pós-colonialidade. Sua mãe deixou de ser cristã quando um hindu, na independente e secular Índia rural, não a contratou por medo de contaminação de casta. Mary se casará com um muçulmano (SPIVAK, 1994, pp. 199-200). 
Ela é, portanto, marcada por uma heterogeneidade aqui temporalmente entendida como uma espécie de intermitente exterioridade (de mais ou menos violenta ou (i)negociada (des)vinculação) a implicar, reiteradamente, nessa sua deriva inter-religiosa, uma situação na qual tenderíamos a reconhecer as condições daquilo a que Jean-François Lyotard chamaria de diferendo. Spivak cita-o, de resto, numa passagem que, transposta em Can the Subaltern Spe$a k$ ?, corresponde ao parágrafo 23 da edição francesa de Le Différend (LYOTARD, 1983, p. 30). Fala-nos aí, em primeiro lugar, de uma certa intransitividade:

In the differend, something asks to be put into phrases, and suffers from the wrong of not being able to be put into phrases right away. This is when the human beings who thought they could use language as an instrument of communication learn through the feeling of pain which accompanies silence (and of pleasure which accompanies the invention of a new idiom) (...) (apud SPIVAK, 2010, p. 55, grifo nosso).

Os seres humanos aprendem, sim... Mas o quê - nessa situação de dor que é, aqui, forçosamente, acompanhada de um inapelável silêncio? Eles aprendem que:

(...) they are summoned by language, not to augment to their profit the quantity of information communicable through existing idioms, but to recognize that what remains to be phrased exceeds what they can presently phrase, and that they must be allowed to institute idioms which do not yet exist (apud SPIVAK, 2010, p. 55, grifo nosso).

A experiência da subalternidade é, portanto, também a do reconhecimento dos limites da linguagem. A questão do subalterno deve, pois, ser entendida como questão da ((im)possibilidade da) representação. Não apenas pelo excesso do seu «real» histórico, em relação às 
mais estritas possibilidades da sua fala, dos quadros da sua linguagem - como posso dizer o que, na minha situação, excede a linguagem de que disponho? -, mas também pelo bloqueio do alcance pragmático-comunicacional do seu discurso - Quem daria ouvidos ao que digo, a partir do lugar que (não) ocupo na sociedade? Mas o que mais nos interessará, aqui, será a forma como, em «Scattered Speculations on the Subaltern and the Popular», a definição de 'subalterno' se vem a apurar num sentido que, ao termo, o desligará de qualquer relação obrigatória com o termo 'popular':

The reasonable and rarefied definition of the word 'subaltern' that interests me is: to be removed from all lines of social mobility. The disciplinary interest of literary criticism is in the singular and the unverifiable. (...) If the thinking of subalternity is taken in the general sense, its lack of access to mobility may be a version of singularity. (...) the world 'subalternity' and the idea of the 'popular' do not inhabit a continuous space. Subalternity is a position without identity (SPIVAK, 2013, pp. 430-431, grifo nosso).

Estas premissas permanecerão, de facto, no horizonte do seu pensamento, mesmo se, volvidos vários anos - quer da publicação inicial de Can the subaltern Speak?, quer da posterior vinda à luz deste último texto - a radicalidade da sua noção de subalterno se atenua, como resulta evidente em «Mapping the Present: Interview with Gayatri Spivak»:

The so-called international civil society is in place now so that the many varieties of what we used to call the subaltern can be accessed. Now, you are quite right in saying that they remain strategically excluded (...). The subaltern now is altogether permeable, rather unlike the definition of subalternity in an earlier conjuncture by the South Asian historians' group where the subaltern is precisely the person outside the circuit of mobility. I have therefore formulated a new notion of restricted permeability (SPIVAK, 2001, p. 11). 
Reincorporado no «circuito da mobilidade» social, o sujeito subalterno continua-ria, no entanto, "estrategicamente excluído", afeto a uma "permeabilidade restrita». Mas, também nessa sua qualidade, continuaria ele a ser aquele com o qual, para Gayatri Spivak, nos é necessário construir uma relação ética que nos coloque no seu lugar - que nos faça, em suma, habitar a sua posição - situada abaixo da escala social. Porquê? Porque apenas assim se poderia, a seu ver, apreender aquilo em que poderia consistir a sua aprendizagem de baixo para cima. Uma aprendizagem quer acerca dos condicionamentos que, sobre ela, recaem e se exercem no sentido da sua exclusão, quer das possibilidades de uma representação contra-hegemónica, que o pudesse resgatar dessa sua condição subalterna. De facto, apesar de reinserido no circuito da mobilidade, o seu afastamento dos lugares cimeiros da estrutura social vê-se, contudo, até acentuado:

The bottom is altogether permeable from above. The academic woman with the cell phone. But the permeability from bellow up into the area of the dominant is not only as restricted as, but more restricted than it was before. The investigation of the subaltern is not the real problem for me now because that kind of permeability is now in place. (...) But I will say that, if one tries to do that, then it is this immense heterogeneity of the subaltern, even subaltern languages (SPIVAK, 2001, pp. 11-12, grifos nossos).

Qual seria o sentido que poderia, então, tudo isto fazer, para a leitura a que aqui nos propomos, a respeito de Imani e de certas personagens femininas de Mulheres de Cinza? Seria, porventura possível considerá-lo, aqui, sem um necessário aprofundamento da sua relação com a questão da «representação»? 


\section{Sombras do presente: duas formas de representação...}

Um dos pontos essenciais de Can the Subaltern Speak? prende-se, como se sabe, com a forma como Gayatri Spivak ali se socorre do alinhamento entre o Marx de $\mathrm{O} 18$ do Brumário de Louis Bonaparte e o Antonio Gramsci de A Questão Meridional. Esse ponto assenta, em primeiro lugar, na caraterização que Marx faz dos pequenos proprietários de parcelas que, na França dos meados do século XIX, se verão representados por Louis Bonaparte:

Os camponeses detentores de parcelas constituem uma massa imensa, cujos membros vivem em situação idêntica, mas sem que entre eles existam múltiplas relações. O seu modo de produção isola-os uns dos outros, em vez de os levar a um intercâmbio mútuo. (...) O seu campo de produção, a parcela, não admite no seu cultivo nenhuma divisão social do trabalho (...). A parcela, o camponês, a família; e ao lado, uma parcela, outro camponês e uma outra família (MARX, 2008, p. 518).

Pelo facto de assim se constituírem, na sua diferença - enquanto massa imensa e grupo social distinto, dada a sua partilha destes traços comuns - dir-se-ia que eles formariam uma classe. Mas o isolamento que os desliga uns dos outros implica a ausência de uma "consciência de classe» que se quisesse transformadora da sua condição, pois esta última pressupõe, em Marx, conforme lembra

1 Deixamos, aqui, de lado, por falta de espaço e economia de meios, a crítica de Gayatri Spivak a Michel Foucault e a Gilles Deleuze, segundo a qual o seu esquecimento da divisão internacional do trabalho e a sua crítica do conceito de representação supõem não apenas a sua cumplicidade na reprodução das condições de produção do subalterno no Terceiro Mundo, mas também a inexistência, no seu pensamento, de uma teoria da ideologia e, com ela, de uma semiótica que, criticamente aplicada ao discurso, deveria permitir discernir a sua própria reinscrição daquele «sujeito soberano" que as suas teorias tanto criticam, sob a forma de um Outro transparente. 
Spivak, um segundo nível de consciência, em cujo horizonte a necessidade da representação em política - a Vertretung (o 'falar por') - se coloca:

Although not identified with nature, the family here is constellated with what Marx calls 'natural exchange', which is, philosophically speaking, a 'place-holder' for use value. 'Natural exchange' is contrasted to 'intercourse with society', where the word 'intercourse' (Verker) is Marx's usual word for 'commerce'. (...And) it is in the area of this intercourse that the feeling of community leading to class agency must be developed (SPIVAK, 2010, p. 21).

A evocação de Marx sublinha, assim, quanto à palavra representação, a necessidade de destrinça do seu duplo sentido. Estético, por um lado: pois os pequenos proprietários constituíam uma classe, uma vez encarados esteticamente, isto é, pela nossa perceção da sua partilha daquelas caraterísticas comuns... E político, por outro: destituídos dessa consciência em segundo grau, marcados pela inexistência do sentimento da sua pertença a esse coletivo, eles não constituíam nenhuma classe... Esta diferença interessa, diretamente, à questão do subalterno - de que, aliás, o exemplo de Marx se constituía já como que uma sugestão antecipada. E as críticas de Gilles Deleuze e Michel Foucault ao conceito de representação não têm, de facto, em conta a necessidade desta destrinça que, a Spivak, lhe parece decisiva. Nestes últimos:

Two senses of representation are being run together: representation as 'speaking for', as in politics, and representation as 're-presentation', as in art or philosophy. (...) The two senses of representation - within the state formation and the law, on the one hand, and in subject-predication, on the other - are related but irreducibly discontinuous (SPIVAK, 2010, p. 28, grifo nosso). 
Esses dois sentidos correspondem, em alemão, aos vocábulos vertretung (a representação no sentido do 'falar por') e darstellung (a representação no sentido do 're-presentar', do fazer presente). A conclusão de Marx é, então, a seguinte:

Na medida em que subsiste entre os camponeses detentores de parcelas uma conexão apenas local e a identidade dos seus interesses não gera entre eles nenhuma comunidade, nenhuma união nacional e nenhuma organização política, não formam uma classe. São, portanto, incapazes de fazer valer o seu interesse de classe em seu próprio nome, quer por meio do parlamento, quer por meio de uma Convenção. Não podem representar-se, antes têm que ser representados (2008, p. 519, grifo nosso).

É a inexistência de laços sociais fomentados pela relação comercial, que neles impede que se estabeleça o sentimento coletivo da sua diferença, ou da sua pertença a um grupo distinto. É isso que acaba por lhes impor o isolamento, essa espécie de orfandade em que se traduz o desamparo em que vivem. É o que os levará, em suma, na ausência de uma organização política própria, à necessidade de serem representados (Vertretung). Este tipo de descrição alinha-se, em Marx, com a caraterização do «subalterno" levada a cabo por Antonio Gramsci. Como nos mostra Guido Liguori, no seu «Subalterno e subalterni nei 'Quaderni del carcere'”, é Gramsci quem observa, no Quaderno 25, quanto ao seu caráter «desagregado» ou atomizado, a sua dificuldade de unificação:

La storia delle classi subalterne è necessariamente disgregata ed episodica: c'è nell'actività di queste classi una tendenza all unificazione sia pure su piani provvisori, ma essa è la parte meno appariscente e che si demostra solo a vittoria ottenuta. Le classi subalterne subiscono l'iniziativa della classe dominante, anche quando si rebellano; sono in istato di difesa alarmata (GRAMSCI, 1975, apud LIGUORI, 2016, p. 97 grifos nossos). 
É aqui - nesta passagem - a primeira vez que Gramsci se refere às "classes subalternas", no plural. Um plural que indiciaria já, para nós, o que mais adiante se definirá como o problema da «agência». E Guido Liguori não deixa de observar, de facto, a respeito desse plural:

In primo luogo, possiamo notare che la «classe dominante» è una (al singolare), le «classi subalterne» sono più di una: l'espressione "classi subalterne» indica um insieme variegato di classi e ceti sociali. Esse subiscono l'iniziativa della classe dominante ma cercano di difendersi (LIGUORI, 2016, p. 98).

Ele parece, portanto, indiciar não apenas a sua dificuldade de união numa frente comum, mas também o seu caráter passivo-reativo e defensivo, diante das iniciativas da classe dominante. Gramsci diz-nos, além disso, no Quaderno 15, que:

Nei gruppi subalterni il fenomeno («della mancanza di generazione che abbia potuto educare i giovani» - G. L.) si verifica più spesso e in modo più grave, per la difficoltà, insita nell'essere "subalterno", di una continuità orgânica dei ceti intelletuali dirigenti e per il fatto che per i pochi elementi che possono esistere all'altezza dell'epoca storica è difficile organizzare ciò che gli americani chiamano trust dei cervelli (GRAMSCI, 1975, apud LIGUORI, 2016, p. 115).

Tal afirmação confirma, no plano diacrónico, o que anteriormente se notou, do ponto de vista sincrónico, quanto ao caráter desagregado e atomizado das "classes subalternas». A sua dificuldade de organização, de reunião dos mais aptos, marca-se, também, na tendencialmente inexistente continuidade de educação dos mais jovens. No entanto, é o que Gayatri Spivak nos diz, em «Scattered Speculations on the Subaltern and the Popular", ainda a propósito daquela anterior passagem de $\mathrm{O} 18$ do Brumário de Louis Bonaparte, 
que nos chama a atenção para aquele aspeto que, aqui, nos parece fundamental:

That passage (from Marx), about the difference between the two ways of being a class, was what gave me a sense of what I later learned to call the difference between subalternity and agency. Agency was the name I gave to institutionally validated action, assuming collectivity, distinguished from the formation of the subject, which exceeds the outlines of individual intention. The idea of subalternity became imbricated with the idea of nonrecognition of agency (SPIVAK, 2013, p. 432, grifo nosso).

O problema do subalterno seria, portanto, precisamente este: o problema da agência, aqui entendida nos termos de uma ação institucionalmente validada. Se dizemos que o sujeito subalterno não é ouvido é, precisamente, por essa ausência de validação da sua ação. Ora, como é que estes traços se coadunarão com as personagens de Mulheres de Cinza? Seria aqui preciso começar por notar que se trata de uma família desenraizada, fora do seu lugar de crença e de proveniência. Circunstância decorrente da vida errante do avô, organizador de expedições para o interior africano e comerciante de escravos, isso manifesta-se, na família que o acompanha, por um lado, pela estranheza da sua forma de vestir:

Eu e a mãe éramos as únicas mulheres que não vestiam os sivanyula, os tecidos de cascas de árvore. As nossas vestes, compradas na cantina do português, cobriam o nosso corpo, mas expunham-nos à inveja das mulheres e à cobiça dos homens. (...) Chikazi Makwakwa nascera em terras do sul. (...) A mãe era uma mabuingela, esses que caminham à frente para limparem o orvalho do capim (COUTO, 2015, pp. 24-25).

Por outro lado, quer nos seus hábitos, quer nas relações que a estruturam. Numa discussão entre a mãe e o pai de Imani, apercebemo-nos, com efeito, de que se trata de uma família cujas matrizes 
culturais oscilam entre as tradições próprias às suas origens e os hábitos (monogâmicos) dos colonizadores:

-Você não gosta de mim, Katini!

- Quem disse?

- Então por que é que você só me tem a mim? Há tantos por aí com várias esposas...

- Não sou como esses VaTsongas que acumulam mulheres como se fossem cabeças de gado... Além disso, escolhemos ser civilizados, não foi?

- Escolheu você. E por causa da sua escolha os nossos filhos desistiram de nós (COUTO, 2015, pp. 55-56)

Ora, este sentido de desenraizamento faz-nos pressentir, em Chikaze Makwakwa, uma situação que se poderia descrever como aquela a que - em «La double séance» - Jacques Derrida chamaria a situação do «entre (/ antre) deux»... (O que seria próprio do que designa por hymen, na sua leitura de Mallarmé):

Rappel: l'hymen (...) produit um effet de milieu (...). Opération qui «à la fois» met la confusion entre les contraires et se tient entre les contraires. Ce qui compte ici c'est l'entre, l'entre-deux de l'hymen. (...). Mais ce milieu de l'entre n'a rien à voir avec un centre. L'hymen entre, dans l'antre. Entre peut aussi bien s'écrire avec un $a$. Les deux (e)/(a)ntres, ne sont-ils pas le même? (DERRIDA, 1972, p. 240).

Os dois «entre» / «antro(s)» são, de facto, o mesmo. E isto tanto quanto o isolamento, a peculiar singularidade do subalterno serão, também potencialmente afetos à fronteira das / entre as culturas aqui em jogo. E são-no, também, tanto quanto se trata, no seu respetivo entre-lugar, de relações de sujeição a códigos antagónicos que, por incompatíveis entre si, se mostram, portanto, insuscetíveis de autolegitimação discursiva. A queixa de Chikaze Makwakwa refe- 
ria-se ao seu solitário confinamento, à sua condição de única esposa, contrária à prática polígama das famílias tradicionais em seu redor. Ao que seria preciso acrescentar o vício da bebida, em Katini Nsambe - conforme se pode ver neste diálogo, entre Imani e Chikaze:

- Está com medo que o pai lhe bata?

- Já sabe como é: ele bebe, ele bate. (...)

- É incrível como o pai nunca desconfiou que a mãe mente.

- E eu minto?

- Claro que mente. Quando ele lhe bate e a mãe chora de dor. Não mente?

- Esta doença é um segredo, o seu pai não pode suspeitar (COUTO, 2015, pp. 29-30).

Chikaze sofria da síndrome de Riley-Day. Ora, o que a sua insensibilidade à dor física ali sublinha é, não apenas a degradação moral, inscrita na necessidade da simulação da sua (inexistente) dor, mas também o deprimente espetáculo daqueles cometimentos, entretanto tornados numa prática reiterada, de geração em geração:

Mistério sem entendimento: o modo como o pai conciliava em si tão opostas almas. Sóbrio, a sua delicadeza era a de um anjo. No toldar do álcool, convertia-se na mais maléfica das criaturas. (...)

- A sua mãe também era espancada?

- A avó, a bisavó e a trisavó. Prepare-se para ser espancada também você (COUTO, 2015, p. 30).

Assim, também por isso, a condição de Chikaze se diria limítrofe. Simultanea-mente por dentro e por fora dos hábitos dos VaTsongas (um nome de etnia bantu que, recobrindo o Sul de Moçambique, abrangia vários grupos e, frequentemente, se estendia aos VaChopi), ela permaneceria, ao mesmo tempo, por dentro e por fora do seu casamen-to. É uma situação insustentável, que mostra bem o quanto 
a leitura de Marx se ajustaria, aqui, aos casos de subalternidade que, como o de Chikaze, se revelariam marcados pela ausência de nexo de pertença, de falta de consciência de classe ou de impossibilidade de integração identitária. Numa passagem em que reflete sobre a tradução inglesa da passagem de Marx - e a considera, ao mesmo tempo, cuidadosamente, no seu original alemão -, Spivak insiste em sublinhar-nos o que aí lhe parece fundamental ler:

Because of the absence of infrastructural institutions, which are the condition and effect of class consciousness, "they ['the peasant proprietors'] could not make their class interest count", to have what they are saying and doing be recognized as such. The early subalternists accepted this as the challenge of their new historiography (SPIVAK, 2013, p. 432, grifo nosso).

A pergunta que se nos impõe parece-nos, portanto, ser esta: não sofreriam, aqueles pequenos proprietários de parcelas, de que Marx nos fala, do mesmo tipo de desintegração sócio-identitária, ou do mesmo tipo de isolamento e de desamparo em que a personagem de Mia Couto se vê mergulhada? Não será, essa, a situação propícia ao anseio por uma figura política paternal que, como Louis Bonaparte, os ajudasse a dissipar os receios causados pela precariedade das suas condições de vida? Uma tal experiência do entre não suporia, nela, portanto, um certo abismo ou desamparo, um certo recolhimento ou retraimento, uma certa experiência do antro - «antro: caverna, gruta natural, profunda e obscura (...) lugar vazio, côncavo, obscuro, de breu» (DERRIDA, 1972, pp. 240-241), cuja etimologia nos remeteria para o sânscrito: "antara, fenda, caverna» (DERRIDA, 1972, p. 241)? Pois que seria preciso não esquecer - conforme nota Derrida, na sua leitura do Littré - que «antara significa propriamente o intervalo e liga-se assim à preposição latina inter» (DERRIDA, 1972, p. 241). A experiência do entre (/ do antro) pode, portanto, ser a do entre-lugar em que o subalterno se vê despojado de qualquer pos- 
sibilidade de agência, de qualquer nexo de pertença e, assim, colocado numa fronteira que se lhe afigura como um abismo que não consegue transpor. E de facto, impotente para mediar e apaziguar os ânimos entre Katini e Dubula, seu filho predileto, Chikaze suicida-se, pouco depois da morte de Dubula, por que saíra ele de casa? Por ser partidário das tropas de Ngungunyane, o que o punha em confronto direto com o pai, partidário da presença dos portugueses em Nkokolani:

Uma semana decorrera desde o falecimento de Dubula e nenhuma ave regressara aos nossos céus. Na madrugada de domingo a mãe amanheceu pendurada na grande árvore do Tsontso. Parecia um fruto seco, um morcego escuro e murcho. Fomos chamar o nosso pai que, cauteloso, se aproximou arrastando os pés. Sob a larga copa, ele se sentou a contemplar o corpo como se esperasse que dele brotassem folhas (COUTO, 2015, p. 325).

Mantenhamos, por enquanto, em reserva, esta figura do «morcego». Pois ela nos reconduzirá, mais adiante, ao centro de uma fábula cujo sentido se revelará essencial à compreensão do que aqui estará em causa. As culpas de Katini, aos olhos de Chikaze, relacionavam-se também com a sua ideia de Imani estudar na Missão do padre Rudolfo Fernandes, perto de Makomani. Como ficamos a saber, em A Espada e a Azagaia:

O meu pai, Katini Nsambe, viu na catequese mais do que uma conversão religiosa: era uma porta abrindo-se para o mundo dos brancos. Essa era a intenção: que eu, Imani, me desembrulhasse da minha origem. Que escapasse de mim para um outro destino, sem retorno, sem raça, sem passado (2016, p. 123).

O que haveria de colocar a filha numa espécie de limiar semelhante ao de sua mãe - embora com a diferença do seu empoderamento, por uma educação a que a mãe não tivera acesso. O certo é, contudo, 
que Katini chegará - mais tarde, em A Espada e a Azagaia - a destinar Imani à prostituição junto dos oficiais portugueses (COUTO, 2016, pp. 84-86), pondo-a a render (COUTO, 2016, pp. 169-172) nas casas noturnas da italiana Bianca Vanzini, em Lourenço Marques. Ora, para Chikaze Makwakwa, exposta à influência dos brancos, também Imani se tornava, já em Mulheres de Cinza, gradualmente exterior e morria, assim, para as tradições da sua terra natal... De facto, quando Katini Nsambe responde a Chikaze, eis a forma como ela reage:

- Ainda temos Imani.

- Imani vai sair. Aliás, já há muito que ela não está aqui.

Falava como se me não enxergasse. Acheguei-me e toquei-lhe no braço: - Estou aqui, mãe.

- Você já saiu, filha. Você fala connosco em português, dorme com a cabeça para o poente. E ainda ontem falou da data do seu aniversário. Onde aprendera eu a medir o tempo? Os anos e os meses, disse ela, têm nomes e não números (COUTO, 2015, p. 56).

Qual era, portanto, a diferença de Imani? O seu próprio nascimento fora marcado por um fenómeno insólito, que estaria na origem dos equívocos a que se prestará o seu sucessivamente obliterado nome próprio.

\section{Da «impossibilidade de ser eu mesma»: ou a mulher sem nome...}

Ora, é a propósito do nome de Layeluane - a avó paterna - que deparamos, em Mulheres de Cinza, com um elemento algo misterioso e premonitório, essencial à nossa abordagem da figura de Imani. É que essa avó está ainda viva na altura em que Imani é gerada por Chikaze. O que se confirma pelo facto de Imani ter estado presente«eu não teria senão uma dezena de anos de idade» (COUTO, 2015, p. 129) -, quer quando Tsangatelo deixa Nkokolani para ir para a África 
do Sul, quer posteriormente, na cena que tem lugar, entre o mensageiro, que dele traz notícias, e a avó (COUTO, 2015, pp. 133-136):

Ofereci ao visitante uma casca de coco cheia de nsope. O homem permaneceu impassível, a examinar a bebida. Recordei, não sei por que razão uma velha cantiga de infância: 'Que belos são os pés dos mensageiros...' os pés do mensageiro foram entrando na canção como se me conduzissem para longe da aldeia (COUTO, 2015, pp. 133-134).

Em que consiste então, este insólito mistério? É pela sua evocação das crenças tradicionais, quanto à nomeação dos recém-nascidos, que ficamos a saber como se envolve o nome de Layeluane, na inicial nomeação de Imani:

Diz-se, em Nkokolani, a nossa terra, que o nome do recém-nascido vem de um sussurro que se escuta antes de nascer. Na barriga da mãe, não se tece apenas um outro corpo. Fabrica-se a alma, o moya. Ainda na penumbra do ventre, esse moya vai-se fazendo a partir das vozes dos que já morreram (COUTO, 2015, p. 19).

E seria justamente aí, ainda na penumbra do ventre materno, que o futuro nome se entreteceria, na alma do recém-nascido: «Um desses antepassados pede ao novo ser que adote o seu nome. No meu caso, foi-me soprado o nome de Layeluane, minha avó paterna" (COUTO, 2015, p. 19, grifo nosso). E é aqui que reside o intrigante mistério: Layeluane não é ainda um «antepassado» quando o seu nome lhe "é soprado", ainda na penumbra do ventre materno, ao menos no sentido em que o são, por exemplo, os «ausentes», por terem já falecido. Por que razão terá, então, o seu nome ali surgido? De facto, a autenticidade desse nome não é verificada à primeira pelos adivinhos de quem o pai de Imani se socorre:

Como manda a tradição, o nosso pai foi auscultar um adivinho. Queria saber se tínhamos traduzido a genuína vontade desse espí- 
rito. E aconteceu o que ele não esperava: o vidente não confirmou a legitimidade do batismo. Foi preciso consultar um segundo adivinho que, simpaticamente, contra o pagamento de uma libra esterlina, lhe garantiu que tudo estava em ordem (COUTO, 2015, p. 19).

Alguns sinais viriam, então, a intensificar-se:

Contudo, como nos primeiros meses de vida eu chorasse sem parar, a família concluiu que me haviam dado o nome errado. Consultou-se a tia Rosi, a adivinha da família. Depois de lançar os ossículos mágicos, a nossa tia assegurou: «No caso desta menina, não é o nome que está errado; a vida dela é que precisa ser acertada" (COUTO, 2015, p. 19).

Em que sentido, no entanto, deveria esse acerto ocorrer? Katini sentir-se-á, a prin-cípio, impotente para resolver aquele tipo de pendência. E dela incumbe a mãe, Chikaze:

E foi o que ela fez, ao batizar-me de «Cinza». Ninguém entendeu a razão daquele nome que, na verdade, durou pouco tempo. Depois de minhas irmãs falecerem, levadas pelas grandes enchentes, passei a ser chamada de "a Viva». Era assim que me referiam, como se o facto de ter sobrevivido fosse a única marca que me distinguia (COUTO, 2015, pp. 19-20, grifo nosso).

Como se deveria, então, entender a razão deste outro nome - Cinza? É ainda Chikaze quem nos ajudará a pensá-lo:

Chikaze Makwakwa interrompeu-me os pensamentos: - Sabe como morreu a sua avó? E não esperou pela resposta. Fulminada por um relâmpago. Foi assim que ela morreu.

- E por que se lembrou disso agora?

- Porque é assim que quero morrer. Era o seu pretendido desfecho: sem corpo, sem peso, sem réstia para sepultar (COUTO, 2015, p. 31). 
Uma iluminação súbita: a pulverização instantânea do corpo atingido... Eis aquilo em que "Cinza» nos faria pensar. Tratava-se, desta vez, da avó materna de Imani:

Sempre que desabava uma tempestade, a nossa mãe (diz Chikaze) saía a correr pelos campos e ali permanecia, braços erguidos, a imitar uma árvore seca. Esperava a descarga fatal. Cinzas, poeirase fuligem: era o que ela sonhava vir a ser. Nesse desejo da avó ganhava razão o meu anterior nome. Foi o que a mãe me quis lembrar (COUTO, 2015, p. 31, grifo nosso).

E a que propósito se lembrava Chikaze daquilo?

- Dei-lhe esse nome para a proteger. Quando se é cinza, nada nos pode doer. (...) - Agora vá buscar seu pai. Ele sente ciúmes de nós.

- Ciúmes?

- De mim, por não lhe dar toda a atenção; de si, porque foi educada pelos padres. Você pertence a um mundo onde ele nunca poderá entrar (COUTO, 2015, p. 32).

Mas por que se faria necessária essa proteção? Não era Chikaze que "cantarolava», na presença de Katini Nsambe, «uma velha canção, um ngodo tradicional. Era um lamento de mulher, queixando-se de já ter nascido viúva» (COUTO, 2015, p. 29, grifo nosso)? O que aproximava então Layeluane da avó materna, enquanto "mulheres de Cinza», senão esse seu antecipado estatuto de mulheres "viúvas», a quem, na sociedade patriarcal, tal como na posição do sujeito subalterno, nenhum homem parecia dar ouvidos? Poderiam elas falar? Talvez o nome pudesse ser uma proteção, sim, caso o seu pressuposto mágico de poder fosse o de antecipar e prevenir a violência e o descaso. $\mathrm{O}$ certo, porém, é que o nome Cinza sugeria, também, a possibilidade da aniquilação do seu portador antes de qualquer testemunho. O que supõe, precisamente, a posição do subalterno, tal como Spivak o descreve, nas primeiras versões de Can The Subaltern Speak? Como nos 
diria Jacques Derrida, em Poétique et politique du témoignage, na sua evocação de «Aschenglorie», de Paul Celan:

La cendre, c'est aussi le nom de ce qui annihile ou menace de détruire jusqu’à la possibilité de témoigner de l'anéantissement même. C'est la figure de l'anéantissement sans reste, sans mémoire, sans archive lisible ou déchiffrable. (...) Telle serait la seule condition tu témoignage, sa seule condition de possibilité comme condition d'impossibilité - paradoxale et aporétique (DERRIDA, 2005, pp. 13-14).

Também aqui «Cinza» seria uma alegoria dessa paradoxal condição de todo o testemunho - cuja possibilidade da sua própria impossibilidade o tornaria, antes de mais, urgente ou premente. Ora, por que é que o nome Cinza não adere à personagem de Imani? Talvez, muito simplesmente, porque «o meu primeiro ímpeto é reagir. $\mathrm{O}$ melhor, porém, será proceder como sempre fiz: adiar a disputa, fingir obediência» (COUTO, 2017, p. 89; grifo nosso). O padre Rudolfo chegará a dizer-lhe, em A Espada e a Azagaia:

- Os que batem à nossa porta estão de passagem. Abre-lhes a casa mas mantém fechada a tua alma. Referia-se à minha atração pelo sargento. Mas o padre falava, também, de si mesmo. Um homem entre mundos, uma criatura entre fronteiras (COUTO, 2016, pp. 104-105, o último grifo é nosso).

Rudolfo assim a aconselhava a que não depositasse demasiadas esperanças no seu amor pelo sargento português Germano de Melo: «Não deixo de escutar o que os outros pretos dizem de ti. E confesso uma coisa, minha filha: antes fosses branca» (COUTO, 2016, p. 104). Pois...

Mais que a uma raça, eu pertencia a uma amaldiçoada espécie: era amiga dos brancos. Atirar-me-iam à cara essa condição como se faz aos loucos e aos leprosos. 
- Acabarás, disse ele, sentindo inveja de teu desvalido irmão. (...)

- Esta é a triste lei do mundo: os que existem pela metade acabam sendo duplamente odiados (COUTO, 2016, p. 104).

Eis um dos traços da sua condição... A juntar a outros: «porque não nasci para ser pessoa. Sou uma raça, sou uma tribo, sou um sexo, sou tudo o que me impede de ser eu-mesma» (COUTO, 2015, p. 20). Mas, mesmo na qualidade de assimilada, ela possui uma aguda consciência das suas origens:

Mas eu sabia como tinham apagado as marcas da minha origem. Durante toda a infância, longe dos meus pais, o padre patrulhara-me os sonhos logo ao despertar, anulando os noturnos recados dos que me antecederam. Para além disso, o sacerdote Rudolfo Fernandes corrigia-me o sotaque como quem apara as unhas a um cão. Eu era preta, sim. Mas isso era um acidente de pele. Ser branca seria a minha única profissão (COUTO, 2016, p. 86, grifo nosso).

E seria para pôr cobro àquele seu inicial desacerto (ou àquele seu excesso) de «Vida» - como diria a "tia Rosi, a adivinha da família»... (COUTO, 2015, p. 19), pois que Imani se tinha, também, chamado «a Viva» (COUTO, 2015, p. 20) - que Katini Nsambe acabaria por intervir:

O resto da história ainda é mais nebuloso. A certa altura o meu velho reconsiderou e, finalmente, se impôs. Eu teria por nome um nome nenhum: Imani. A ordem do mundo, por fim, se tinha restabelecido. Atribuir um nome é um ato de poder, a primeira e mais definitiva ocupação de um território alheio. Meu pai, que tanto reclamava contra o império dos outros, reassumiu o estatuto de um pequeno imperador (COUTO, 2015, p. 20, grifos nossos).

E, no entanto: porquê «um pequeno imperador»?... E por que razão se diria ser, aquele, "um território alheio»? Em que poderia, então, consistir este «restaurar da ordem do mundo» senão, justamente, em 
isentá-lo do que, forçosamente, lhe escaparia já, em Imani? Como? Eis o que ficamos a saber, em A Espada e a Azagaia:

Há muito que Imani sabia dos fantasmas que atormentavam o velho Katini Nsambe. Sempre soube, sempre fingiu não saber. E tudo tinha a ver com o modo como fora nomeada desde a infância. Todos na aldeia sabiam o que se ocultava naquela escolha. Imani é o nome que se dá às filhas de um pai desconhecido (COUTO, 2016, 249).

Imani era e não era filha de Katini. Ora, o que significava Imani? Ela mesmo discorrerá sobre o estranho nome que seu pai lhe impõe, em Mulheres de Cinza:

Chamo-me Imani. Este nome que me deram não é um nome. Na minha língua materna «Imani» quer dizer «quem é?». Bate-se a uma porta e, do outro lado, alguém indaga: - Imani? Pois foi essa indagação que me deram como identidade. Como se eu fosse uma sombra sem corpo, a eterna espera de uma resposta (COUTO, 2015, pp. 18-19, o primeiro e último grifos são nossos).

Porquê, no entanto, «uma sombra sem corpo»? Não nos recordaria ela, em certo sentido, a própria escrita, na sua mais constitutiva espectralidade? Ora, «Imani» é, de facto, o nome que vem a estancar uma vertiginosa série de anteriores nomeações: Layeluane, Cinza, a Viva... Fá-lo mediante a obliteração ${ }^{2}$ a a firmação da negação da possibilidade do nome próprio.

2 Note-se que, em De la grammatologie, do filósofo francês Jacques Derrida, é precisamente essa uma das suas definições de escrita em geral: uma «obliteração do nome próprio", enquanto nome representa-tivamente adequado: "Si l'on cesse d'entendre l'écriture en son sens étroit de notation linéaire et phonétique, on doit pouvoir dire que toute société capable de produire, c'est-à-dire d'oblitérer ses noms propres et de jouer de la différence classificatoire, pratique l'écriture en général» (DERRIDA, 1967, p. 161). 


\section{Da obliteração do nome: a singularidade, o neutro...}

Essa obliteração do nome traz, consigo, uma espécie de reviravolta, uma vez que a interrogação "quem é?» suporia - uma vez nominalizada - a impossibilidade de qualquer nomeação outra. A anteceder o patronímico, «Imani» suporia, de resto, o insidioso contratempo de uma certa reversão irónica: «Quem é Nsambe?», eis a ironia que o seu nome continha. E não sem razão. Vejamos porquê. De facto, Katini não era apenas tocador de marimbas. Era, também, seu fabricante - ofício apenas reservado a alguns mestres:

A fabricação de marimbas foi o que, naquele dia, me fez madrugar para acompanhar o meu velho à floresta das grandes figueiras a que chamamos mphama. Desde menina me incumbiram de uma missão que deveria caber a um rapaz: subir às árvores para capturar morcegos (...) (COUTO, 2015, pp. 101-102).

Pois era com «as membranas das asas, depois de secas, (que se) forravam as caixas de ressonância (...) para o fabrico das marimbas» (COUTO, 2015, p. 102). Mas Imani impressionava-se com a morte das «fêmeas que amamentavam os filhotes. (...) Até que, daquela vez, (...) ganhei coragem para declarar: - Desculpe, pai. Mas eu não volto lá em cima nunca mais.» (COUTO, 2015, p. 103). Katini Nsambe espanta-se. Pergunta-lhe, então: «- Está com pena dos morcegos?» E contemporiza: «Eu (...) vou-lhe dizer por que percebo muito bem essa sua recusa» (COUTO, 2015, p. 103). Eis a fábula que lhe conta:

E contou-me uma história antiga, que escutara de seus avós. Naquele tempo, os morcegos cruzavam os céus com a vaidade de se acreditarem criaturas sem semelhança neste mundo. Certa vez, um morcego tombou ferido numa encruzilhada de caminhos. Passaram por ali uns pássaros e disseram: olha, um dos nossos! Vamos ajudá-lo! (COUTO, 2015, pp. 103-104). 
O que fizeram eles, então?

(...) levaram-no para o reino dos pássaros. O rei das aves, porém, ao ver o morcego moribundo comentou: ele tem pelos e dentes, não é um dos nossos, levem-no daqui para fora. E o pobre morcego foi depositado no lugar onde havia tombado. Passaram os ratos e disseram: olha, é um dos nossos, vamos salvá-lo! (COUTO, 2015, p. 104).

O que fariam, então, os ratos?

Conduziram-no à presença do rei dos ratos que proclamou: tem asas, não é dos nossos. Levem-no de volta! E conduziram o agonizante morcego para o fatídico entroncamento. E ali morreu, só e desamparado, aquele que quis pertencer a mais do que um mundo. (...)

- Entendeu, filha?

- Acho que sim (COUTO, 2015, p. 104).

Ao que seu pai observará, então: «- Duvido. Porque esta história não é sobre morcegos. É sobre você, Imani. Você e os mundos que se misturam dentro de si». (COUTO, 2015, 104). O que nos faria pensar na instância do neutro, tal como o definiu Maurice Blanchot, em «René Char et la pensée du neutre», em L'entretien infinit: "o neutro é o que não se distribui em qualquer género: o não geral, o não genérico, como o não particular» (1969b, p. 440). O mesmo se diria da peculiar «singularidade» do subalterno, ou da sua diferença, afastado ele de todas as linhas, quer de integração identitária, quer de mobilidade social. Pois como diria Gayatri Spivak: «Ninguém pode dizer 'Eu sou um subalterno' em qualquer língua que seja» (2013, p. 431). Porquê? Porque:

Singularity was a questioning of the universal-particular dyad. The singular is repeated, with a difference. That's how the 'human' is repeated-in-difference in single humans, prior to the construction of personhood or individuality. It is a powerful 
concept, anchored in good sense, questioning both universalism and identitarianism (SPIVAK, 2013, p. 436).

Que terá esta repetição-na-diferença que ver com a questão da «agência» e, por conseguinte, com a do subalterno? Nada, precisamente... E, ao mesmo tempo, tudo... Porquê? Porque:

If the repetition of singularity that gives multiplicity is the repetition of difference, agency calls for the putting aside of difference. Agency presumes collectivity, which is where a group acts by synedoche: the part that seems to agree is taken for the whole. I put aside the surplus of my subjectivity and synedochize myself, count myself as the part by which I am metonymically connected to the particular predicament, so that I can claim collectively, engage in action validated by that very collective (SPIVAK, 2013, pp. 436-437, grifos nossos).

De facto, se a subalternidade representa uma "posição sem identidade» é precisa-mente porque não existem, para ela, linhas sociais de mobilidade que lhe permitam a partilha desse sentido de relações de formação social que, no caso da classe e do género, lhes servem de base de/para a sua (negoci)ação:

Subalternity is a position without identity. It is somewhat like the strict understanding of class. Class is not a cultural origin, although there is working class culture. It is a sense of economic collectivity, of social relations of formation as the basis of action. Gender is not lived sexual difference. It is a sense of the collective social negotiation of sexual difference as the basis of action. Race assumes racism. Subalter-nity is where social lines of mobility, being elsewhere, do not permit to the formation of a recognizable basis of action (SPIVAK, 2013, p. 431).

Ou, então, a questão do neutro, uma vez mais. Por quê? Porque sem semelhança «neste mundo»... - nenhum dos restantes animais 
reconhece, no morcego da fábula, nem a espécie, nem o indivíduo. Regido por um certo paradigma metonímico de classificação, o mundo das espécies deixa-o de fora. Reconhece-o, sinedoquicamente, mas apenas na sua incompletude, uma vez que ele se mostra incapaz de se abstrair da sua diferença. A história do morcego é, portanto, a da impossibilidade da «agência» e da identificação. Observa Blanchot:

En une simplification évidemment abusive, l'on pourrait reconnaître, dans toute l'histoire de la philosophie, un effort soit pour acclimater et domestiquer le «neutre» en y substituant la loi de l'impersonnel et le règne de l'universel, soit pour récuser le neutre en affirmant la primauté éthique du Moi-Sujet, l'aspiration mystique à l'Unique singulier (BLANCHOT, 1969b, p. 441, grifo nosso).

Ora, não seria isto justamente o que se passaria, com os esforços de Katini por domesticar Imani - atribuindo-lhe uma "impessoalidade», «uma não-identidade»: «Quem é?» - com que se visava a recobrir, anular a sua heterogeneidade, a sua singularidade? Katini chegará a dizer-lhe, em A Espada e a Azagaia, quando ela o ameaça com o seu próprio suicídio, por estar ele a destiná-la à prostituição: «Você não pode matar-se. E sabe por quê? Porque não tem vida nenhuma» (COUTO, 2016, p. 261). Não se lhe deveria reservar, então, o neutro - o entre / o antro / a singularidade - como a instância pela qual a escrita se revelaria, politicamente, democrática e se esquivaria à coação exercida por toda a espécie de paradigma? Eis o que Blanchot nos diz - desta vez em «La voix narrative (le «il», le neutre)»:

La voix narrative, elle porte le neutre (...) en ceci que (...) l'exigence du neutre tend à suspendre la structure attributive du langage, ce rapport à l'être, implicite ou explicite, qui est dans nos langues, immédiatement posé, dès que quelque chose est dite. (...) La voix narrative est, sous ce rapport, la plus critique qui puisse, inentendue, donner à entendre (BLANCHOT, 1969a, pp. 566-567, grifo nosso). 
Daí a observação de Barthes, em Le neutre - cours au collège de France (1977-1978): «compreende-se agora para onde tende o Neutro. (... E cita então Blanchot): 'a exigência do neutro tende a suspender a estrutura atributiva da linguagem <é isto, aquilo> (...)’ (2002, p. 76). Para acrescentar:

Parce qu'il vise radicalement le rapport de l'être et de la langue, le Neutre ne peut se contenter des modes (modalités), qui codent officiellement dans la langue l'atténuation de l'affirmatif: la négation, la dubitation, le conditionnel, l'interrogation, le souhait, la subjectivité, etc. (...) car les modes font encore partie de l'être (2002, pp. 76-77, grifo nosso).

Ora, o "problema de linguagem» envolvido pelo neutro consistiria, então, em "suspender todas as categorias", como nos acrescenta Roland Barthes (2002, p. 76, grifo nosso): «ou ainda, para ser mais preciso»... em "falar implicando, dando a entender que todo o paradigma está mal formulado, o que é desviar a própria estrutura do sentido» (2002, p. 77 , grifos nossos). Em que consistiria, então, esse desvio? Na sua suspensão... Posto que, se o neutro supõe a intrusão da alteridade:

Le «il» narratif, qu'il soit absent ou présent, qu'il s'affirme ou se dérobe, qu'il altère ou non les conventions de l'écriture - la linéarité, la continuité, la lisibilité - marque ainsi l'instrusion de l'autre entendu au neutre - dans son étrangetéirréductible, dans sa perversité retorse. L'autre parle (BLANCHOT, 1969a, p. 564, grifos nossos).

...Essa intrusão do outro ou da multiplicidade nos tornaria indecidível qualquer escolha. Mesmo a de género. Tal parece ser, justamente, o caso em Imani. Por exemplo, quando assiste aos espetáculos que Katini promove, de aldeia em aldeia:

Fosse como fosse, a verdade é que aquele compasso viril me arrancava do mundo e, embora a dança fosse exclusivamente executada por homens, no meu recatado lugar eu mantinha todo o corpo em mo- 
vimento. E era como se uma outra pessoa dançasse dentro de mim. Talvez essa pessoa fosse «a Viva», talvez fosse «Cinza», talvez fossem todas as que em mim viveram (COUTO, 2015, p. 105, grifo nosso).

Porque, como a seguir ela acrescenta: «naquele momento eu ficava isenta de ter corpo, desobrigada de ter memória. Eu era feliz» (COUTO, 2015, p. 105, grifo nosso). Não surpreende, portanto, que, no final de $O$ Bebedor de Horizontes, quando a voz do "escritor» recém-chegado lhe pergunta "posso gravar Dona Imani?», se ouça, depois, ao repassar-se a gravação:

«Podes gravar, mas não me fotografes. Olha bem para mim, meu neto. Esta criatura que vês à tua frente não é feita de um corpo único. São muitos corpos colados, cada um feito num tempo, cada um vindo de uma terra diferente. O coração é desta aldeia, os braços são de Mutimati e as pernas já não sei de onde são. (...) Não me fotografes, meu neto, porque eu não termino em mim» (COUTO, 2017, p. 363).

O que significaria, então, essa multiplicidade? Como nos ensinaria José Gil, no seu Caos e Ritmo, (2018, p. 74-75), tratar-se-ia, então, de um «corpo espectral». Ele funcionaria, aqui, como uma espécie de síntese disjuntiva que o tornaria inabordável - nesta «criatura que vês à tua frente» (COUTO, 2017, p. 363) - pela fotografia. Invisível na multiplicidade dos meus espaçamentos e temporizações, «eu não termino em mim»... A própria Imani, autora intraficcional dos manuscritos que estariam na base da trilogia romanesca As Areias do Imperador, da autoria de Mia Couto, se dispõe, no final, a ceder o espaço da sua autoria ao jovem escritor branco, recém-chegado, que ela toma, já com 95 anos, por seu neto: «está aqui toda a minha vida. Leva estes cadernos se achares que merecem ser conhecidos. Assina-os como sendo tu o autor, não me importo. Desde que digas que és meu neto, o neto de Imani Nsambe» (COUTO, 2017, p. 366). Um problema de agenciamento? Sem dúvida... Quem era ela? Poderia ela falar? Quem lhe daria ouvidos? 
RECEBIDO: 10/11/2020 APROVADO: 21/06/2021

\section{REFERÊNCIAS}

BARTHES, Roland. Le neutre - cours au Collège de France (1997-1978). Paris: Seuil, 2002.

BLANCHOT, Maurice. La voix narrative (le 'il', le neuter). L'entretien infinit. Paris: Gallimard, 1969a, pp. 556-567.

René Char et la pensée du neutre. L'entretien infinit. Paris: Gallimard, 1969b, pp. 439-450.

COUTO, Mia. Mulheres de Cinza. Lisboa: Caminho, 2015.

COUTO, Mia. A Espada e a Azagaia. Lisboa: Caminho, 2016.

COUTO, Mia. O Bebedor de Horizontes. Lisboa: Caminho, 2017.

DERRIDA, Jacques. La double séance. Dissémination. Paris: Seuil, 1972.

DERRIDA, Jacques. Poétique et politique du témoignage. Paris: L'Hèrne, 2005 .

La violence de la lettre: de Lévi-Strauss à Rousseau. De la grammatologie. Paris: Minuit, 1967, pp. 149-202.

GIL, José. Caos e Ritmo. Lisboa: Relógio d’Água, 2018.

GRAMSCI, A. Quaderni del carcere. Torino: Eunaudi, 1975.

LIGUORI, Guido. Subalterno e subalterni nei "Quaderni del carcere”. International Gramsci Journal, 2(1), 2016, 89-125. Acessível em: https://ro.uow.edu.au/gramsci/vol2/iss1/24/

LYOTARD, Jean-François. Le différend. Paris: Minuit, 1983.

MARX, Karl. O 18 do Brumário de Louis Bonaparte. Trad. de José BarataMoura e Eduardo Chitas. In Obras Escolhidas I. Lisboa: Edições Avante, 2008, pp. 430-534.

SPIVAK, Gayatri C. Quem Reivindica a Alteridade? Trad. de Patricia Silveira de Farias. In HOLLANDA, Heloísa Buarque de. Tendências e Impasses: o feminismo como crítica da cultura. Rio de Janeiro: Rocco, 1994, pp. 187-205.

Mapping the present: interview with Gayatri Spivak. New Formations - 45: The Rendez-vous of Conquest (Winter), 2001, pp. 9-23.

Can the Subaltern Speak? In MORRIS, Rosalind C. (ed.) Can the Subaltern Speak? -Reflections on the History of an Idea. New York: Columbia UP, 2010, pp. 21-78. 
Scattered Speculations on the Subaltern and the Popular. An Aesthetic Education in the Era of Globalization. Cambridge / Massachusetts: Harvard UP, 2013, pp. 429-442.

\section{MiNicuRRículo}

José Paulo Cruz Pereira nasceu na Ilha de Moçambique. Licenciou-se em Línguas e Literaturas Modernas pela Universidade Clássica de Lisboa, onde defendeu, em 1996, uma tese de Mestrado em Literatura Comparada, mais tarde publicada com o título Uma Cartografia transtornada: a Guernica de Carlos de Oliveira. Doutorou-se em 2004, também em Literatura Comparada, pela Universidade do Algarve, onde leciona as disciplinas de Literaturas Estrangeiras de Língua Portuguesa II e Comunicação na Contemporaneidade e tem ensinado em diversos mestrados - nas áreas dos Estudos Pós-coloniais e dos Estudos Culturais, as quais investiga, como membro do grupo 7 do Centro de Literaturas e Culturas Lusófonas e Europeias. 